\title{
LA COCINA CHILOTA: EL GENUINO LUGAR DE ENCUENTRO DE UNA COMUNIDAD BORDEMARINA
}

\author{
Antonio Sahady V. ${ }^{1}$ \\ José Bravo S. ${ }^{2}$ \\ Carolina Quilodrán R. ${ }^{3}$ \\ (Dibujos de Felipe Gallardo G.) $)^{4}$
}

\section{Introducción}

Todo grupo social, para sobrevivir a las exigencias del marco geográfico que le da cobijo, está obligado a someterse a sus leyes naturales. Y muy particularmente a las condiciones climáticas que, a menudo, definen su modo de vida. En 1922 Vidal de La Blache 5 ya planteaba la necesidad de ponderar la interacción que se producía entre el ambiente natural en que un pueblo vive y su cultura.

Las condiciones climáticas de Chiloé -a menudo extremas-, amén de su insularidad y lo despedazado y hostil de su geografía convierten a este te-

1 Chile. Director, académico e investigador. Instituto de Restauración Arquitectónica. Facultad de Arquitectura y Urbanismo, Universidad de Chile. Chile. Correo Electrónico: asahady@uchile.cl.

2 Chile. Investigador. Instituto de Restauración Arquitectónica (InReAr). Facultad de Arquitectura y Urbanismo, Universidad de Chile.Chile.Correo Electrónico: marcelobravo2000@yahoo.com. rritorio en un lugar excepcional. Los fríos permanentes y las lluvias de implacable intensidad no consiguen arredrar la voluntad de los pescadores que se hacen a la mar cotidianamente en busca del alimento para la familia. El chilote es océanodependiente; su vida depende del mar que le envuelve, que le proporciona el suministro vital y que se hace carretera a la hora de trasladarse de una localidad a otra. El mar es su ambiente, su escenario siempre presente, su lugar de paso y su objetivo final.

3 Chile. Investigadora. Instituto de Restauración Arquitectónica (InReAr). Facultad de Arquitectura y Urbanismo, Universidad de Chile. Chile. Correo Electrónico: carolinnaqr@yahoo.es.

4 Chile. Académico e investigador. Instituto de Restauración Arquitectónica. Facultad de Arquitectura y Urbanismo, Universidad de Chile.Chile.Correo Electrónico: felipe.gallardogastelo@gmail.com.

5 Paul Vidal de La Blache, 1922. 
Pocas veces el paisaje y el clima resultan más gravitantes en un pueblo como ocurre con los chilotes; el determinismo geográfico es, en este caso, un hecho manifiesto. El antropólogo Carlos Munizaga, ${ }^{6}$ a través de un estudio etnográfico que centra en Chiloé, expone que todo grupo social, para adaptarse a la realidad que le toca en suerte vivir, debe, necesariamente, elaborar las respuestas para enfrentar el mundo exterior.

Lo primero es su segunda piel, esto es, la vestimenta apropiada; lo segundo, la vivienda. Para los chilotes, el corazón y el estómago de la vivienda se concentran en la cocina. Es, en definitiva, el cálido sitio donde convergen los intereses culturales y económicos. Al calor del fogón se tejen las leyendas y los mitos. Pero también rehacen las transacciones comerciales.

No extraña que Rodolfo Urbina escribiera tres obras sobre Chiloé y que se haya detenido en la cocina, asegurando que se trata del genuino lugar de encuentro de la familia. En "La vida en Chiloé en los tiempos del fogón" evoca la época en que los amigos se reunían en derredor del rústico artefacto de hierro que irradiaba calor y mansedumbre. Allí, alumbrados por el fuego central, departían, planificaban y elaboraban el mañana.

Los tiempos han cambiado. En los sectores urbanos, aquel artefacto tosco y oscuro que tragaba leña y devolvía calor ha dado paso a un aséptico objeto

Carlos Munizaga, 1971. blanco que funciona con gas o electricidad y cuyo objetivo central es cocer o freír alimentos. Otro objeto, distinto del anterior, cumple con la tarea de entibiar el ambiente cuando se enfría: la estufa. El habitante de la ciudad exige adelantos porque en su nuevo horizonte aspira a una mejor calidad de vida, indiferente a la historia y las formas de comunicación del pasado. Pero en las zonas rurales aún las costumbres tienden a mantenerse, en el entendido que la tertulia familiar es una necesidad.

Los actuales estudios acerca de la vivienda del futuro ya no se conciben sin tener en consideración el bienestar de sus moradores. Pero muy pocos agregan como ingrediente fundamental el respeto por la cultura de quienes habrán de habitarla. Indiscutiblemente, cuando no está investida de la anónima expresión de la arquitectura mecánicamente multiplicada, de espaldas a los dictados del mercado inmobiliario, se logran resultados de alta calidad.

Cada grupo social elabora su propia expresión material -también la inmaterial- a fin de enfrentar adecuadamente el determinismo geográfico del lugar al que pertenece. Pero es en la vivienda, justamente, donde el hombre extrema su ingenio y su sabiduría práctica. Se trata de dotar su hábitat de las mejores condiciones posibles para enfrentar el mundo exterior, satisfaciendo no sólo los múltiples requerimientos urbanos, sino todo cuanto ocurre puertas adentro. 
Una investigación del Instituto de Restauración Arquitectónica (2006) señala, entre sus conclusiones, que muchos de los componentes de la cultura chilota han sido anulados por el abrumador proceso de la globalización. Los efectos de este fenómeno también se introducen en la cocina chilota, reduciendo sus dimensiones y subvirtiendo su organización espacial.

Por su parte, la diseñadora Rocío Ebensperger en su memoria de título "KüTRALWE, cocina a leña para la Décima Región" (2006), propuso un nuevo modelo de cocina a leña en la viviendas sociales, como respuesta a los problemas que tenían los chilotes en las localidades urbanas. Se trataba de preservar, con el apoyo del artefacto propuesto, los lazos tradicionales amenazados.

Con más razón que en otros lugares, la vivienda en Chiloé precisa de condiciones especiales, toda vez que el modo de vida de los habitantes así lo sugiere, concordando también con Claval (1987): los grupos humanos tienden a adaptarse o guarecerse del medioambiente en que se insertan, de acuerdo al estadio cultural al cual pertenecen. Por lo tanto, defenderse de las adversas condiciones exteriores es la primera consigna. Pero no es menos determinante la vocación gregaria de su gente, que se reúne en torno a la fuente de calor.

7 Proyecto Fondecyt No 1061126: “La arquitectura y fiestas religiosas de Chiloé. Sustento tangible e intangible de un patrimonio de la humanidad en busca de la difusión".

\section{Construyendo un estudio}

Dos caudalosos ríos del conocimiento han confluido en este artículo: el patrimonio arquitectónico y la geografía cultural. Aun cuando el fenómeno descrito acoge diversas vertientes del saber, prevalecen ciertas áreas mediante las cuales es posible cualificar la conducta de una comunidad y verificar de qué manera se da el correlato entre ese comportamiento y el territorio físico en el cual tiene lugar. Observado desde dos perspectivas simultáneas, es perfectamente plausible aproximarse a conclusiones que coadyuven a propuestas futuras: la cocina como un motivo central de estudio en la cultura de los pueblos del archipiélago chilote.

Derivado de una investigación desarrollada entre 2006 y 2007 en el seno del Instituto de Restauración Arquitectónica ("La arquitectura y fiestas religiosas de Chiloé. Sustento tangible e intangible de un patrimonio de la humanidad en busca de la difusión", proyecto Fondecyt 1061126), el motivo de la cocina chilota es una de las manifestaciones tangibles más determinantes de la cultura del archipiélago.

En la certeza de que la cocina-fogón es el punto de partida de las primeras viviendas de los pueblos que habitaron el archipiélago y que ella represen-

revista invi №67 / Noviembre 2009 / Volumen № 24: 155-172 157 
ta una de las más poderosas manifestaciones de cultura vernácula, bien merece la pena abordar este problema en los futuros diseños de la nueva vivienda social en esas latitudes.

Una revisión exhaustiva de las soluciones habitacionales diseminadas en las islas de Chiloé deja claro que, pese a las muchas variantes que se dan, hay ciertas características que se tornan constantes y que son las que terminan por perfilar la identidad de la vivienda isleña. Descontadas las especificaciones materiales y constructivas -que constituyen el marchamo físico y morfológico de las edificaciones sureñas- aparecen los espacios interiores que otorgan una personalidad propia a las viviendas. Pero ningún espacio como la cocina concentra con más intensidad el alma de la familia chilota, núcleo y corazón de las tertulias y de la convivencia cotidiana.

Ningún rasgo de la cultura isleña ha sido más resistente y refractario a los cambios que impone el mundo sin rostro de la globalización contemporánea que la cocina chilota de las comunidades rurales. El conocimiento de este universo es una lección de humanidad que bien debiera ser, al menos, divulgado.

Surge entonces la pregunta: el diseño de un espacio arquitectónico, como la cocina de una vivien$\mathrm{da}$, ipuede llegar a condicionar la conducta de sus moradores? ¿O son éstos, impelidos por la fuerza de la tradición, los que impongan sus términos, a pesar de las adversas condiciones del diseño?
La respuesta es difusa. Un catastro prolijo de la situación actual podría acercarnos a la realidad, abriendo un campo de investigación aún poco frecuentado. El camino de la exploración ayudaría a confinar el problema en acercamientos sucesivos.

Lo primero: una intensa revisión bibliográfica acerca del tema de la cocina a leña, su habitación y su relación social, económica y cultural, por parte de sus moradores y usuarios. En particular, la cocina-habitación, estrechamente vinculada a la actividad cotidiana, al modo de vida y al pensamiento mágico de los isleños.

Hasta la fecha, el estudio entre la cocina como espacio de encuentro y su relación con la cohesión y solidez de la familia chilota ha sido escasamente profundizado. Por lo general, este aspecto se toca de forma tangencial. El énfasis se ha puesto en los aspectos físicos y dimensionales antes que en los humanos y sociales. Es preciso, en este punto, mediante apoyo bibliográfico, escudriñar la historia de los aborígenes en torno al fuego, procurando explicar las costumbres que hasta hoy perduran.

Lo que importa es demostrar documentadamente la importancia de la cocina como núcleo de coincidencia familiar, donde confluyen los intereses culinarios, sociales, económicos. También los referidos a la cultura y al ocio.

Algunas fuentes confiables de la Facultad de Arquitectura y Urbanismo y, también, de la Facultad de Ciencias Sociales y Humanidades de la Univer- 
sidad de Chile -antecedentes bibliográficos, fotográficos y audiovisuales- permiten explicar, bajo el alero de la historia y la etnografía, cómo se ha ido consolidando un modo de vida de vigorosa identidad con el lugar y su clima asociado.

Frente a los embates de la globalización, la cultura local -especialmente la de los poblados rurales- levanta sus murallas defensivas. ¿Hasta cuándo logrará resistir? Un iluminador texto de Carlos Munizaga ("Notas sobre adaptación del medio físico de Chiloé: vivienda y vestuario", 1971) expone los atributos de la cocina como habitación vernácula en Chiloé, deteniéndose en las distintas dimensiones que caracterizan este recinto de la vivienda.

\section{Contexto y Problemática}

La condición de insularidad y el rigor de un clima marítimo templado lluvioso han impuesto su marco en la cultura chilota. Es un hecho que estas condiciones ambientales se vinculan directamente con la supervivencia biológica del individuo. La geografía y el clima exigen un nivel mínimo de adaptación, que es el que hace posible la vida. De ello depende el tipo de vivienda y todo el acondicionamiento físico y ambiental asociado. Y depende, desde luego, la indumentaria a utilizar.

Los mecanismos de defensa de la especie humana, ya puestos en marcha desde el principio de los tiempos, también tienen su lugar cerca de los australes mares del sur. Más que luchar contra la naturaleza, el hombre chilote ha decidido lo único sensato: adaptarse a

OPINIÓN: La cocina chilota: El genuino lugar de encuentro de una comunidad bordemarina / Antonio Sahady V., José Bravo S., Carolina Quilodrán R. ella. Ha optado por una existencia más bien gregaria, de puertas adentro, de proximidad y de afectos. De forma natural, materializa el concepto de familia. En estos términos la consecuencia lógica es la expresión de su hábitat, resultante de las costumbres adquiridas y poco a poco consolidadas por la tradición

Una respuesta a estas características es la vivienda vernácula. Allí la cocina ocupa un lugar de privilegio: es el recinto donde se preparan las comidas; pero es, sobre todo, el recinto destinado al encuentro familiar. En la tibieza de esa atmósfera hogareña se planifican las actividades cotidianas, se habla de lo humano y lo divino, se cuentan historias, fábulas, leyendas, adivinanzas. Allí mismo se suelen realizar, además, actividades económicas como tratos y trueques, tan propios de los campesinos chilotes (Foto 1).

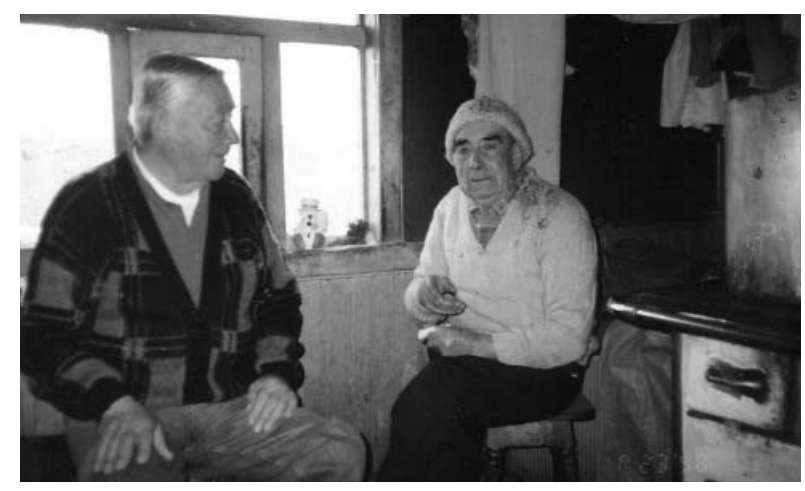

FOTO 1. Tertulia al calor de la cocina a leña. Autor: Marcelo Bravo, 2000.

No puede desconocerse que un 44\% de la población total de Chiloé vive en sectores rurales, en forma dis-

revista invi № 67 / Noviembre 2009 / Volumen № 24: 155-172 159 
persa en el campo, sostenida por una economía agrícola, siempre dependiente del régimen local de lluvias. El sistema de calefacción -cocina o cocina-fogón a leña- es un imperativo si se quiere conseguir una temperatura cercana a los 20 grados centígrados.

El 56 \% restante corresponde a entidades urbanas chilotas, distribuidas en tres ciudades y seis pueblos como núcleos de concentración demográfica. Estas áreas, en cambio -además de las manifestaciones de la arquitectura residencial chilota emplazadas en el sector central de las urbes-, coexisten con un nuevo patrón arquitectónico, localizado principalmente en los sectores altos y las periferias de los centros urbanos. En ellos se han dispuesto algunas normas de construcción derivadas de las políticas estatales de vivienda, tendientes a reducir el espacio útil en las habitaciones de uso más intenso. Imposible que allí se dé el ambiente propicio para la tertulia y el encuentro consuetudinario. El morador termina, indefectiblemente, cediendo paso al artefacto a gas y con ello resigna la posibilidad de mantener vivos los afectos familiares. Junto con este cambio de escenario físico se propicia una paulatina pérdida de las relaciones humanas conforme desaparece el fuego de la cocina a leña y también el modo de vida familiar, comunitario, cálido y cordial, tan característicos del isleño.

\section{La cocina chilota, un lugar de encuentro legado por los primeros aborígenes}

Los pueblos indígenas que cocieron a fuego lento la cultura chilota eran los llamados chonos y veliches. Se instalaron en el territorio entre los $40^{\circ}$ $30^{\prime}$ y $43^{\circ} 30^{\prime}$ de Latitud Sur y $72^{\circ} 50^{\prime}$ y $73^{\circ} 10^{\prime}$ de Longitud Oeste. Desde que vieron la luz, por primera vez, supieron de la sensación de invierno. El frío y las lluvias fueron siempre sus referentes inevitables en el espacio exterior. ¿Cómo no desear un recinto tibio, un hogar que les devolviera el calor disipado a bordo de sus dalcas? ${ }^{8}$ El fuego era la solución. Sus poderes físicos desbordaban hacia el territorio de lo mágico. Se confundieron, también, las necesidades de alimentarse y de atrapar calor, de comunicarse y de ordenar las actividades futuras. Todo en torno a la hoguera.

La cocina a leña es fruto de la natural evolución de la hoguera primordial. Este artefacto hubo de requerir un recinto propio para ser cobijado dentro de la vivienda. Finalmente, la cocina, como recinto, y la cocina a leña, como artefacto, se tornan indispensables.

8 La dalca es la antigua embarcación de los chilotes, cuyo sistema constructivo guarda una relación elemental con el tipo de canoas o piraguas polinésicas que los investigadores alemanes han denominado "Plankenboot" (bote de tablones). 
La historia revela la gravitación que siempre tuvo este lugar en la vida cotidiana del chilote. Chonos y veliches se organizaban socialmente en torno a una hoguera. Ambos pueblos destinaban un sitio que cumpliera con la característica de poder mantener el fuego, que en muchos casos tenía la cualidad de sagrado (Foto 2).

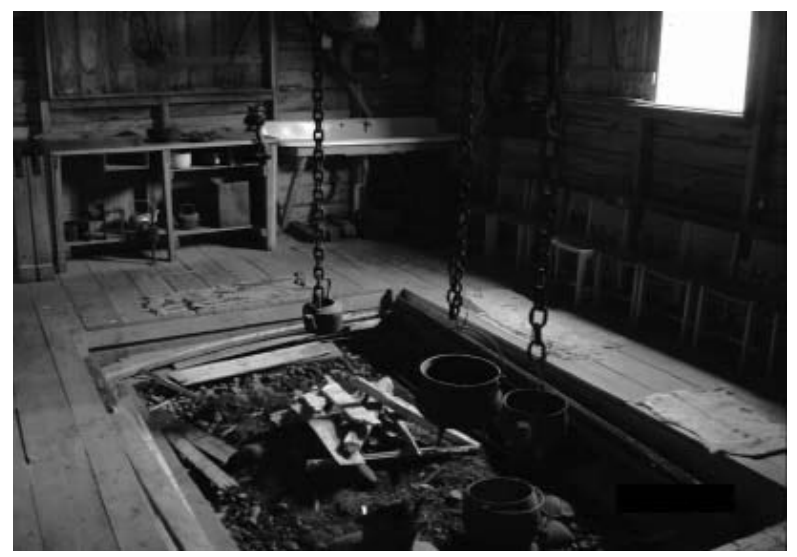

FOTO 2. El fogón chilote, herencia del inveterado fuego producido por los indígenas. Autor: Nicolás Piwonka, 2000.

En el caso de los chonos -pueblo canoero y recolector marino, por excelencia-, su vivienda consistía en una choza o toldo, morada que era muy similar a la de los qawáshqar y otros pueblos fueguinos. A diferencia de los demás, los chonos recurrían, para fabricar el techo, a cortezas, ramas y grandes hojas $y$, de cuando en cuando, a cueros de lobo. ${ }^{9}$

Con estas palabras el Padre Lozano describía la vivienda de los chonos: "...se reducen á unos palos clavados en tierra, y cubiertos los claros con cortezas de árboles, que defienden de recibir el embate de los vientos, más no reparan contra los rigores del frío y sólo á fuerza de fuego las conservan calientes, principalmente, que las forman tan baxas, y estrechas, que en algunas de rodillas tocaban los padres al techo y apenas cabían los dos estendidos. Solo tienen la triste conveniencia de poderlas fácilmente transportar a otro sitio, porque si necesitan hacer viage á sus pescas cargan en su pyraguilla dichas cortezas y palos, y la arman de pronto donde quiera que aportan..."

Reconoce, más adelante, que el área geográfica donde habitaban los chonos era intensamente fría, al extremo que "se yelaban las mesmas ensenadas del mar".

Se explica, así, que el pródigo fuego, instalado en el centro de sus pequeñas casas, constituyese una verdadera bendición. En su interior los hombres descansaban, confeccionaban utensilios o preparaban el

9 La vivienda, según Canals Frau, es la misma en todos los mesolíticos amerindios: "La choza semisubterránea, de sección redonda o rectangular y techo en forma de cúpula, construida con elementos vegetales recubiertos de tierra"( Prehistoria..., p. 404).

10 Pedro Lozano, Historia de la Compañía de Jesús de la Provincia del Paraguay, p.560.

revista invi № 67 / Noviembre 2009 / Volumen № 24: 155-172 161 
alimento. Las mujeres, por su parte, debían bucear para obtener alguna comida, cuando los varones no estaban pescando o cazando en el mar. El borde del fogón era, definitivamente, el lugar destinado a la convivencia en familia y la planificación de roles sociales y económicos para el diario vivir. Cierto es, también -asevera Byron-, ${ }^{11}$ que las largas estancias en esa atmósfera colmada de humo terminaba por irritar los ojos de los presentes. Es que aquellos toldos cobertores no disponían de una abertura superior para permitir el escape del humo, como sí ocurría en las viviendas próximas al Estrecho de Magallanes.

Los veliches, a diferencia de los chonos, eran un pueblo sedentario cuya subsistencia dependía de la actividad agrícola y ganadera. Sus rucas,${ }^{12} \mathrm{em}-$ plazadas en sitios de altura para mantener cierto dominio visual del entorno, estaban construidas con varas gruesas, paja y unos escasos tablones. ${ }^{13}$ De planta rectangular, oval o poligonal, oscilaban entre cinco y seis metros de largo por tres a cuatro de ancho. Las de mayores dimensiones alcanzaban los 20 metros de largo por 10 de ancho. Y aun las había más grandes. Considérese que en el área mapuche-huilliche existían rucas tan grandes

11 Lord Byron, en Cárdenas, 1999.

12 Cañas Pinochet (Estudio..., p. 253) asegura que brico corresponde a choza.

13 Valdivia, en 1551, encuentra vivencias construidas en grandes tablazones, con 2, 4 o más entradas. Motsny afirma que los picunches y huilliches vivían en ranchos de ramas o pircas, a diferencia de los mapuches que lo hacían en rucas. que podían alojar hasta 90 personas. Lo corriente, en todo caso, era que cobijaran alrededor de 30, según testimonios de los cronistas.

Las rucas descritas por Cortés Hojea y Ladrillero (1557), en el Golfo de Coronados (Ancud), tenían entre cuatro y seis entradas. De acuerdo a Brouwer (1643) "sin soberado ni departamentos, cubiertas todas de pasto largo, con una sola puerta pero sin ventanas i con una sola abertura en el techo por donde sale el humo”. Más tarde, González de Agüeros (s. XVIII) se refiere a "mal formados ranchos de tablas... que para tapar las junturas y huecos que median entre ellos, se valen de pedazos de pellejo de carnero y trapos viejos". ${ }^{14}$

Algunos cronistas describen el interior como una habitación única. Otros señalan, en cambio, que en las grandes rucas se producían divisiones o compartimentos que constituían las alcobas de cada familia. Por lo general, cada pareja cocinaba en su propio fogón. Interiormente no existía mueble alguno. De hecho, en un principio no tenían la costumbre de sentarse, ni en el piso ni en troncos; dormían en pellejos o montones de paja o juncos colocados en el suelo y se cubrían con cueros o ponchos, usando

14 Cortés Hojea y Ladrillero, en Cárdenas, 1999. 
como almohada un trozo de madera, o bien, atados de juncos o cueros y, en algunos casos, una piedra. Con posterioridad apareció una plataforma baja y bancos para sentarse, como también otros muebles. Se solía conservar los alimentos - a veces ahumadosen envases de cuero, o bien, en canastos (Foto 3).

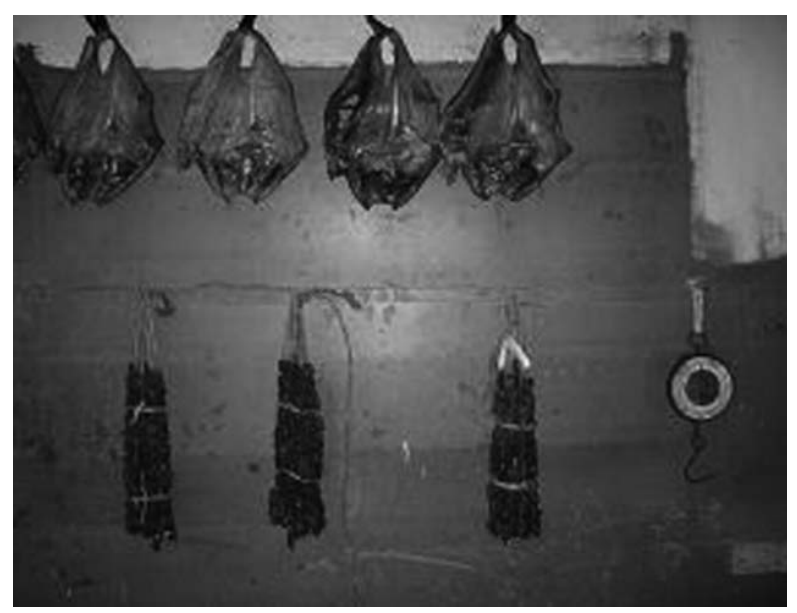

FOTO 3. El ahumado de productos tradicionales, un recurso cultivado desde los ancestros. Autor: Nicolás Piwonka, 2000.

En la cultura mapuche-huilliche el fuego era producido mediante la fricción de un palo puntiagudo que se encajaba en otro agujereado por el medio.

OPINIÓN: La cocina chilota: El genuino lugar de encuentro de una comunidad bordemarina / Antonio Sahady V., José Bravo S., Carolina Quilodrán R.
Para lograrlo, una de las piezas se dejaba en el suelo y se sujetaba con los pies; la otra, sostenida con las manos, se frotaba vigorosamente contra la primera, hasta encender un polvo de aserrín que se había depositado en el trozo agujereado. Con paja u otra materia seca se prendía el fuego. Casi siempre se mantenía encendido dentro de la ruca. Excepcionalmente, se conservaba en ciertas cortezas.

Cuando los españoles se establecieron en suelo sureño dejaron, como en el resto de sus colonias, el sello propio de su arquitectura, inspirada en códigos europeos. En general, se valieron de la tapia para los muros y la teja para las cubiertas. Pero el gran terremoto que asoló la ciudad de Castro, en 1575, obligó a una reconstrucción. Los españoles prefirieron, entonces, echar mano a las técnicas constructivas empleadas por los indígenas. Dos siglos más tarde, San Carlos de Chiloé (Ancud) estaba parcialmente de pie: "Hay ya 138 viviendas, todas de madera con techo de paja, excepto los alojamientos del fuerte y la casa de Gobierno" ${ }^{15}$. En los distintos períodos de la historia se ha tratado de incorporar materiales extraños al medio. Primero fueron las tapias de tierra introducidas por los españoles, luego la construcción a base de cancagua (Ancud), imitando el trabajo del ladrillo de

15 Véase: Rodolfo Urbina, “Los pueblos de Chiloé, génesis de un periplo Urbano". En: revista $C A, \mathrm{~N}^{\circ} 78,1994$ : pp 34-37. Además: Hernán Montecinos, "Arquitectura de Chiloé", en De Toesca a la arquitectura moderna, Facultad de Arquitectura y Urbanismo, Universidad de Chile, 1996: pp 69-80.

revista invi № 67 / Noviembre 2009 / Volumen № 24: 155-172 163 
la zona central y, finalmente, el cemento y planchas de zinc. Sin embargo, siempre se vuelve a la madera, material chilote por antonomasia.

Es justo reconocer, sin embargo, que también los misioneros traspasaron a los indígenas elementos propios de la arquitectura del Viejo Mundo. Dentro de la vivienda, en todo caso, uno de los recintos que mantuvo su rol de lugar de encuentro familiar y comunitario, a la manera indígena, fue la cocina.

En el transcurso del tiempo la ruca fue objeto de transformaciones paulatinas. Pasó a cumplir, en algún momento, la función de cocina-fogón. Actualmente es todavía posible encontrar vestigios materiales de las antiguas estructuras en pesebreras y galpones rurales. Y donde escasea la madera, los techos se siguen cubriendo con material pajizo ${ }^{16}$. A fines del siglo pasado se describía una habitación campesina como un solo cuerpo, que contiene en un extremo el estrado, donde duermen los moradores, y en el otro el fogón donde arde constantemente el fuego. Se agrega que la vivienda era de techo pajizo y en su interior dormían también los animales domésticos. En su entorno se ubicaba el chiquero, el caidizo (allí se encierran las ovejas) y el campanario, donde se guardaban las cosechas.

La cocina-fogón, hoy en día, es utilizada para ahumar carnes y cocinar comidas típicas. También se preparan allí los asados y los curantos, cuando las condiciones climáticas exteriores son adversas (Foto 4 y Figura 1)-

16 Alfred Weber, p. 116, en Cárdenas, 1999.

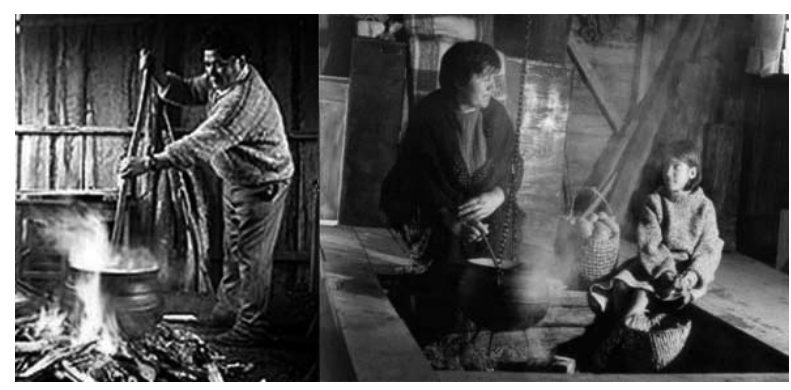

FOTO 4: Campesino en la labor tradicional del yoco (o derretimiento). La transmisión de las destrezas culinarias.

Autor: Nicolás Piwonka, 2000.

\section{SECCIÓN DE LA ESTRUCTURA DE LA COCINA-FOGÓN, PROPIA DE LA VIVIENDA CAMPESINA CHILOTA}

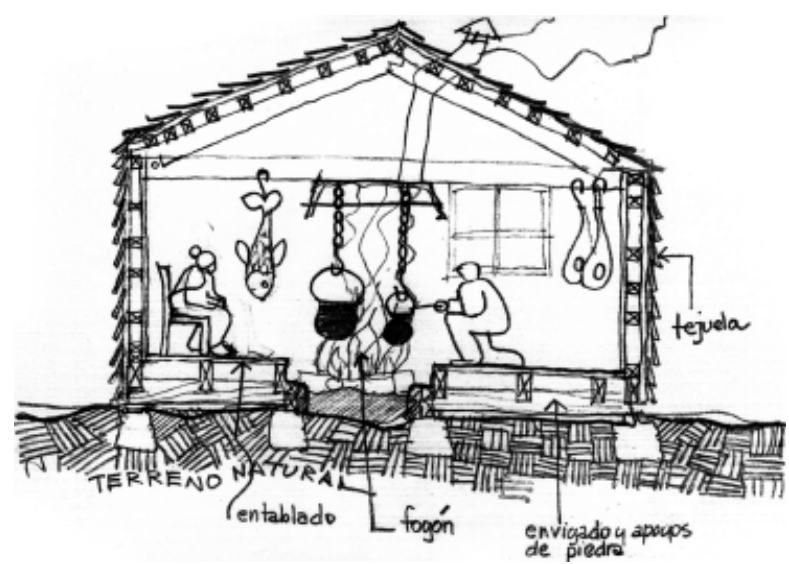

FIGURA 1

Dibujo de Felipe Gallardo, 2008. 


\section{Un espacio para el fuego: la cocina chilota}

En 1971 Carlos Munizaga destacaba, en su estudio etnográfico, la importancia de la cocina como habitación vernácula en Chiloé. En el análisis describe que la cocina-habitación registraba temperaturas de 20 a $22^{\circ} \mathrm{C}$, mientras que en el exterior la temperatura ambiente alcanzaba a $6^{\circ} \mathrm{C}$ en el periodo invernal, demostrando de esta forma por qué la vida cotidiana de los isleños se lleva a cabo en este lugar. También reparó que los chilotes, en los meses de verano, mantenían encendida la cocina durante gran parte del día, a pesar de que las temperaturas oscilaban entre los 20 y $30^{\circ} \mathrm{C}$. Aun así, la familia se reunía en torno al artefacto disipando calor. Este hecho demuestra que tanto la cocina como la habitación que la alberga han encontrado un espacio en las costumbres ya instaladas en este pueblo bordemarino.

A través de su investigación, Munizaga consiguió determinar las distintas dimensiones que convergen en este recinto de la vivienda:

- Espacio Culinario: En la cocina se preparan las principales comidas validadas por la tradición. Entre ellas los milcaos, el curanto a la olla, los chapaleles, el churrasco de papas, el pan amasado (Foto 5).
- Espacio de Calefacción: La cocina representa el fuego vitalizador. Es el lugar de resguardo frente a las inclemencias del clima.

- Espacio Socioeconómico: Es en la cocina donde se convienen, desde tiempos ya remotos, tratos económicos y sociales (entre ellos, matrimonios y bautizos).

Cabe precisar que la cocina es el recinto de confianza de la familia: si el visitante no tiene una relación cercana con los anfitriones, tiene derecho a ser recibido sólo en la sala de estar.

- Espacio cultural: Las tertulias al calor del fogón estimulan la conversación distendida. Se produce, como en ninguna otra parte de la casa y de modo natural, la narración de historias, de leyendas y de mitos. Todo eso, mediante el más antiguo y sencillo recurso de la comunicación, cual es la transmisión oral.

El mismo Munizaga ${ }^{17}$ asegura que, hasta hace casi medio siglo, la casa de los chilotes era similar a la de los veliches: se fundían en ellas las actividades de la cocina-comedor y las del fogón. Lo mismo ocurre hoy día con las viviendas rurales de Chiloé, en las que esta fusión sigue vigente. Se mezclan, sin demasiados escrúpulos, el descuartizamiento de animales con la preparación de alimentos y el almacenamiento de hortalizas y leña.

17 Carlos Munizaga, 1971. 


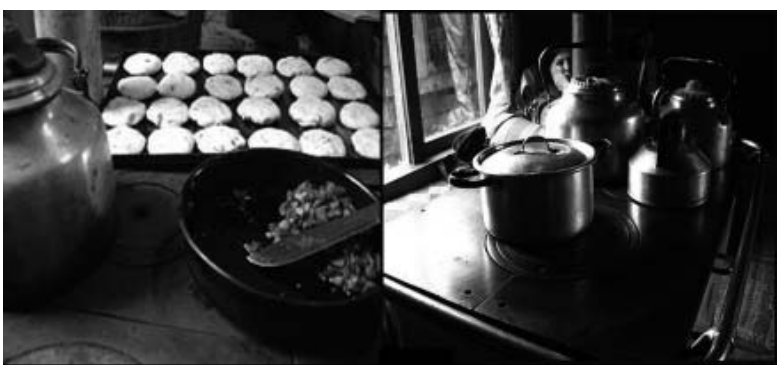

FOTO 5. La cocina chilota, verdadera maestranza del arte culinario. Autor: Nicolás Piwonka, 2000

En la actualidad, cuando la vivienda chilota ha llegado a un alto grado de estandarización en su concepción, diseño y construcción -muy similar a la del resto del país-, se hace necesario que las actividades sean más específicas y que dispongan de recintos propios. Así, en la cocina-comedor, convenientemente higienizada, se preparan los alimentos y se produce el ritual de las comidas. Por su parte, en el sector del fogón se faenan los animales, se ahúman papas, pescados, mariscos y carnes. El mismo calor del fogón sirve para secar el trigo cosechado en temporadas de lluvia. En torno a estas actividades tiende a congregarse la familia campesina chilota (Foto 6).

Hay que precisar, por otro lado, que el uso de la cocina-fogón se hace más intenso en el caso de hogares campesinos más modestos.

166 revista invi № 67 / Noviembre 2009 / Volumen № 24: 155-172

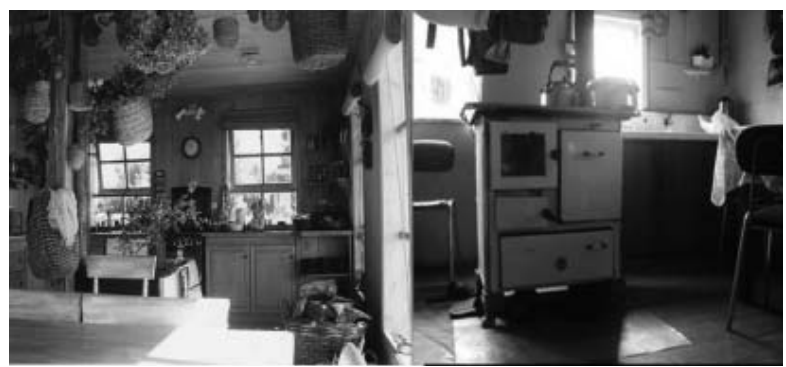

FOTO 6: La nueva cocina chilota, cediendo a las tentaciones del cambio. Autor: Nicolás Piwonka, 2000 y Rocío Ebensperger, 2006.

Cuando se trata de viviendas localizadas en territorios urbanos, es posible discernir diferentes conductas del usuario, según sea su estrato socioeconómico. A modo de ejemplo, la disposición del mobiliario dentro de la cocina es un elocuente indicador:

- En el estrato social medio suele agregarse al artefacto cocina, ciertos electrodomésticos de línea blanca. La misma cocina sirve, a veces, para el secado de ropa, para realizar la cocción de los alimentos. Y constituye, por último, la fuente de calor de la vivienda.

- El estrato social alto, por su parte -más interesado en la comodidad que en la comunicación familiar-, relega a un segundo plano el artefacto cocina a leña e incorpora el uso del gas como combustible, tanto para la cocción de alimentos como para la calefacción del hogar. 
Se renuncia, en este caso, a la interacción social y a la serie de actividades que alienta el calor del fogón (Figura 2).

\section{LA COCINA-COMEDOR DESPOJADA DE IDENTIDAD, OUE PAULATINAMENTE DESPLAZA AL FOGÓN CHILOTE TRADICIONAL.}

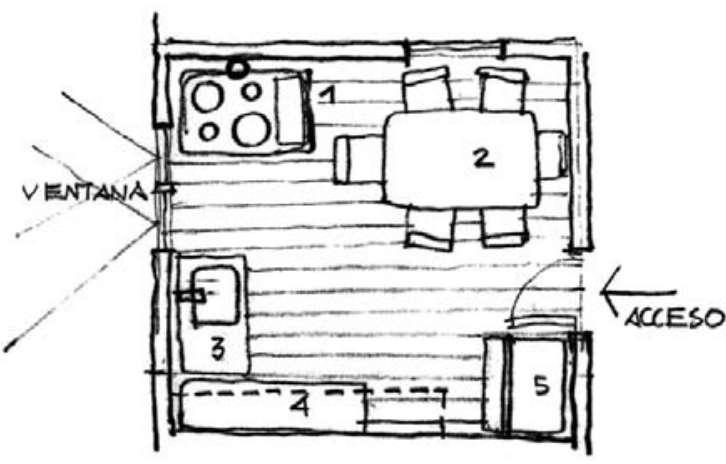

1. Cocina.

2. Comedor.

3. Lavado.

4. Mesón de Preparación + Mueble Aéreo de Almacenamiento.

\section{Refrigerador.}

FIGURA 2

Dibujo de Felipe Gallardo, 2008

Otro autor que reconoce la trascendencia de la cocina-habitación como lugar de encuentro cultural para la existencia del habitante de Chiloé, es Philippe Grenier (1984), que define a la cocina chilota como un lugar donde el isleño come y se calienta y advierte diferencias con el tradicional fogón. En su estudio la define, en comparación con el fogón, como menos rudimentaria. Se traduce en una habitación única, con ventanas, un suelo entablado, de cerámica o de linóleo. Confirma que los chilotes prefieren estar en el interior de sus viviendas, sentados en torno al fuego ancestral, animando una cálida conversación, antes que estar expuestos a las condiciones climáticas existentes. Y es que, amén de las mejores condiciones térmicas, la comunicación es más honda y estimulante. Tanto es así que, como anécdota, el autor afirma que en aquellas moradas en que los muros o ventanas permitan infiltrar alguna brisa del exterior, ellos se apresuran a cubrirla con diarios o revistas viejas.

Además, coincide con otros autores en el siguiente aserto: "la cocina-habitación para los chilotes es un lugar que les permite pasar todos aquellos momentos de su ruda existencia; puesto que allí se pueden encontrar diversos elementos que ocupan para sobrevivir, como alimentos ahumados y alguna que otra herramienta de uso en la faena campesina".

Es común que, arrimadas a los muros, existan banquetas sobre las que reposan frazadas de lana de oveja (o pieles), dispuestas para arropar el sueño de quienes decidan dormir una vez que la noche va desvaneciendo la tertulia. "No es de extrañar 
que los campesinos chilotes nacen, crecen, maduran y mueren junto a la cocina", afirma Munizaga. Y agrega otro antecedente: la cocina, en el ámbito rural, cobra inusitada vida en el momento de transformarse en un salón de baile, cuando se celebran cumpleaños, onomásticos u otros acontecimientos familiares.

Para el historiador Rodolfo Urbina (2002), la cocina, como recinto y como artefacto, ha sido determinante en la forma de vida de los chilotes. ${ }^{18}$ En uno de sus relatos apela a los recuerdos: "Mirando al patio se encontraba la cocina, amplia y acogedora, testimoniando ser la pieza principal donde transcurría la vida familiar o, en su lugar, una pequeña construcción anexa, o cocina-fogón, costumbre tradicional de los vecinos más modestos". Y añade: "se vivía en la cocina la mayor parte del día, porque además cumplía la función de sala de estar y comedor".

La familiaridad con el frío y las lluvias, sin embargo, no eximen a los chilotes de las enfermedades respiratorias: la proximidad al fuego les expone a los bruscos cambios de temperatura al momento de salir a la intemperie. Juan Munizaga (1996) afirma que la gripe, en Chiloé, suele alcanzar propiedades de pandemia, lo que redunda en anomalías diversas, incluyendo una merma en el crecimiento de los niños.

18 Rodolfo Urbina, 2002.

\section{La inevitable globalización}

Como es natural, el cuño del progreso se hace sentir, también, en los lugares más remotos. Chiloé no puede ser la excepción. Acosado por las tentaciones del ciberespacio, también debe defenderse de quienes se esmeran en transformar su territorio. Cada vez resulta más difícil encontrar exponentes genuinos de su arquitectura vernácula. Los propios palafitos han estado en la mira de los demoledores.

Desaparecen sistemáticamente los tipos edificatorios con más identidad, llevando consigo las innúmeras historias contadas en torno al fogón. En su lugar surgen viviendas de planta nueva, ceñidas a los estándares mínimos indispensables. La mezquindad de los espacios se hace más evidente en el recinto cocina, donde queda, como único recurso, instalar una cocina a gas de exiguas dimensiones en el lugar establecido en el proyecto. ¿Dónde tendrán lugar, en ese caso, las tertulias familiares, los encuentros con amigos y vecinos?

Un estudio de Ebensperger, en el año 2006, ${ }^{19}$ determinó que aquellas familias chilotas que viven en casas de menos de $80 \mathrm{~m}^{2}$ no están en condiciones de contar con cocinas a leña: su tamaño excede el espacio destinado para ella. Por tanto, las comidas se preparan en una cocina a gas y el agua caliente para el aseo personal se obtiene del calefón (Figura 3).

19 Rocío Ebensperger, 2006. 


\section{PLANTA DE VIVIENDA SOCIAL DE LAS NUEVAS CONSTRUCCIONES DE CHILOÉ.}

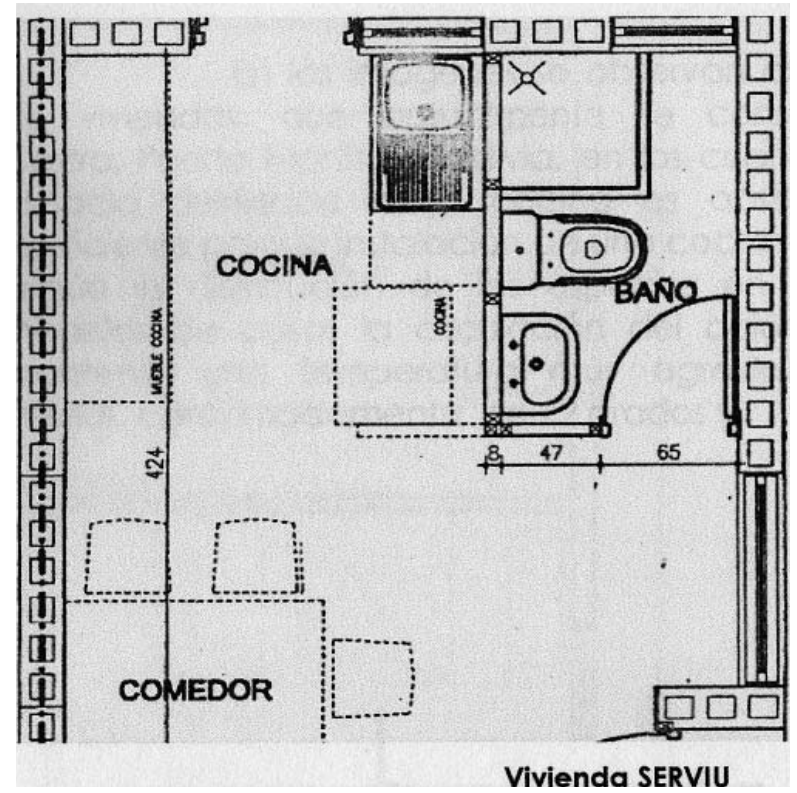

FIGURA 3

Autor: Rocío Ebensperger, 2006.

Algunas viviendas básicas de muy reducido tamaño integran la cocina al resto de las habitaciones. Sin embargo, el calor que proviene de ella no es suficiente para subir la temperatura del resto de la casa. Una casa que ya no se identifica con la isla y menos aún con su cultura vernácula.
Es necesario que, en materia de vivienda, las políticas estatales consideren diseños nítidamente orientados a una cultura que reclama un reconocimiento permanente. La vivienda chilota, como organismo vivo, no puede prescindir del fogón, que equivale a su vientre; y menos aún, a la cocinacomedor, que es su corazón. Pero más allá de las características físicas que singularicen estos espacios, lo que importa es que éstos satisfagan genuinamente las necesidades y motivaciones íntimas de sus usuarios. Ellos son, en último término, el patrimonio intangible más valioso de la isla.

Para Huxley las habitaciones destinadas al encuentro familiar tienen un poderoso contenido mentifacto. ${ }^{20}$ Vale decir, son mucho más que una visión geométrica o física del espacio íntimo, en el cual confluyen simultáneamente las dimensiones histórica, social, económica y cultural, materias propias de las Ciencias Humanas.

Hay que convenir que las nuevas políticas habitacionales, desplegadas en todo el territorio chileno, obedecen a estándares matemáticos, a cifras, a estadísticas. Carecen de espíritu y, por lo mismo, no consideran el factor humano. El legado cultural, las tradiciones ancestrales de un pueblo de vocación marina, no tiene cabida en las decisiones que son primordialmente de orden económico. En consecuencia, las nuevas viviendas chilotas no difieren

20 Julian Huxley, en Bravo, 2004. 
demasiado de las de la zona central y ni siquiera de las del norte: están concebidas con una cocina mínima, como mínimos son todos los demás recintos.

En la actualidad el fogón es casi un imposible. Porque si la vivienda tradicional chilota persiste en su empeño de contar con su artefacto a leña en medio de la gran cocina, no es fácil contar con el combustible necesario. Cada vez la leña es más escasa y la necesidad de recurrir a energías alternativas obliga a un drástico cambio en las costumbres. Pero el calor que proporciona el gas o la electricidad, ciertamente, jamás sustituirá la sugerente visión de las lenguas del fuego envolviendo los leños y ese proceso natural mediante el que la madera se convierte en brasas y finalmente en cenizas. Las tortillas de rescoldo y el tazón de té son los aliados de ese ambiente.

Pocas imágenes ilustran mejor la idiosincrasia chilota que una familia reunida en torno al fogón. Por desgracia, hasta esa condición naturalmente gregaria del hombre isleño ha ido lentamente mutando hacia la creación de mundos individualistas. También hasta allí ha llegado, para quedarse, la costumbre de comunicarse a través de los correos virtuales. Y, como en todo el mundo globalizado, las miradas y la atención tienden a converger en alguna de las pantallas encendidas: el televisor o el computador.

Junto con las manifestaciones físicas se van extinguiendo las expresiones inmateriales, aquello que no es cuantificable y que carece de materia: los afectos humanos, la calidez de la relación familiar, tan auténticamente acrisolados en el fogón de la cocina chilota (Foto 7).

Quedan esperanzas, sin embargo. Mientras existan chilotes conscientes del capital cultural que atesoran, mientras sean fuertes para defender lo que les pertenece, contaremos con un primer bastión. El segundo está en manos de las autoridades, que deben ilustrarse para reconocer y luego comprometerse con la salvaguarda de un patrimonio que no tiene sustituto. Y, sin duda, a los profesionales corresponde interpretar las necesidades de un pueblo para satisfacerlas de forma adecuada. Comprender que por sobre los guarismos, el número de metros cuadrados o los coeficientes de constructibilidad, está la familia, la relación armónica entre sus componentes. Y que los valores de la convivencia, de la amistad, deben ser propiciados con diseños inteligentes y sensibles. La cultura ancestral merece el mayor de los respetos.

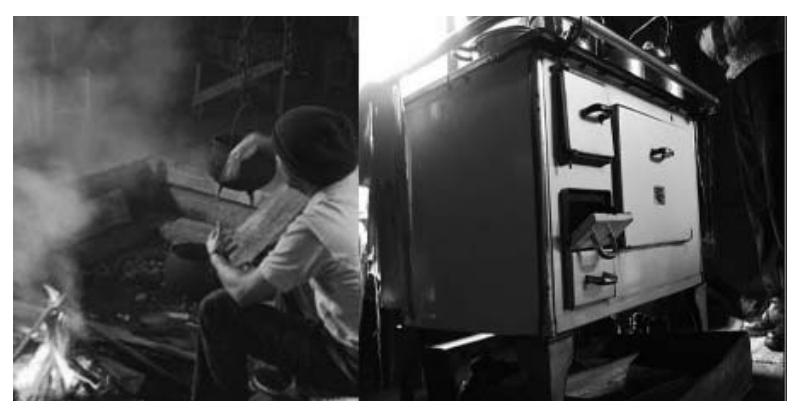

FOTO 7: Del fogón artesanal al artefacto industrializado. Autor: Rocío Ebensperger, 2006. 


\section{Consideraciones Finales}

Hay, sin duda, elementos de permanencia en la cultura chilota que dan identidad al espacio donde habita el hombre isleño. Estas invariantes se asientan en el patrimonio tangible, particularmente en su arquitectura y en las creaciones artesanales. Pero, muy en especial, se alojan en el patrimonio inmaterial. El fogón está en la frontera de ambos. Y su calidad de permanente depende de la resistencia que oponga a los embates externos. La globalización es la amenaza más seria, pues trae consigo un inevitable cambio en las costumbres familiares. Dispara en pleno corazón de la familia chilota, aboliendo la tertulia que se ha producido, espontáneamente, en torno al fogón, desde el tiempo de los aborígenes. Unas cuantas notas finales:

- La habitación destinada a la cocina, de algún modo, ha materializado la condición de cobijo o abrigo que tiene el pueblo chilote. Se explica, así, su condición de "lugar de encuentro", resultado de vivir varios siglos en el particular sistema de comunidad que caracteriza la cultura chilota.

- Estos lugares de encuentro familiar, comunitario y cultural están insertos en la memoria colectiva del pueblo chilote, debido a su valor histórico, social, económico y patrimonial. Más que una visión geométrica o física del espacio en que se encuentra el núcleo familiar, el término lugar de cobijo cultural contiene una poderosa carga espiritual, que calza perfectamente con las definiciones que proponen las Ciencias Humanas como la geografía, la arquitectura, la antropología y la sociología, entre otras.

- Los fundamentos de la presente propuesta son tributarios de una variante antrópica de las Ciencias Humanas - cual es el caso de la Geografía Cultural-, que demuestra que el espacio interior de la vivienda chilota no es estática en el tiempo.

- La cocina-habitación se ha logrado adaptar a los cambios que ha traído consigo la globalización, pero sin llegar a traicionar la vocación que la define: ser el verdadero foco primario de reunión para el pueblo chilote.

- Las políticas de vivienda social dependientes del Estado deberían considerar la excepcionalidad de estos lugares, de modo que los programas de planificación habitacional y todas las acciones asociadas no hagan sino estimular la salvaguardia de todo el patrimonio inmaterial que resguardan. 


\section{Bibliografía}

BRAVO, JOSÉ, La Cultura Chilota y su Expresión Territorial en el Contexto de La Globalización de la Economía. Memoria para optar al Título Profesional de Geógrafo. U. de Chile. Santiago. 2004.

CANALS FRAU, SALVADOR, Prehistoria de América, Editorial Sudamericana, Buenos Aires, 1950.

CAÑAS PINOCHET, ALEJANDRO, La lengua veliche, su probable origen. En: Actes de la Sociéte Scientifique du Chili, año XIV, imprenta Cervantes, pp. 1-20. 1904.

CÁRDENAS, RENATO et al, Los Chono y Los Veliche de Chiloé, Editorial ATELÍ. Castro, Chiloé. 1999.

CAVADA, FRANCISCO JAVIER, Chiloé y los chilotes, Editorial Universitaria, Santiago, 1914.

CLAVAL, PAUL, Espacio, representaciones y normas. Las etnografías, Laboratorio Espacio y cultura, ciudad y civilizaciones. Univ. De París. Francia. 1987.

EBENSPERGER, ROCío. Kütralwe. Cocina a leña para la Décima Región. Memoria para optar al Título Profesional de Diseñador Industrial. U. de Chile. Santiago. 2006.

GRENIER, PHILIPPE, Chiloë et les chilotes - Marginalité et dépendance en Patagonie Chilienne, Editorial EDISUD. Paris. Francia. 1984.

LOZANO, PADRE PEDRO, Historia de la Compañía de Jesús de la Provincia del Paraguay, T. 4, Madrid, 1754-1755.

172 revista invi № 67 / Noviembre 2009 / Volumen № 24: 155-172
MARINO, CÉSAR Y SILVIA BIANCHI, Chiloé: cultura de la madera, Santiago. Chile. 1980.

MONTECINOS, HERNÁN, Arquitectura de Chiloé, en "De Toesca a la arquitectura moderna", Facultad de Arquitectura U. De Chile, 69-80 pp. 1996.

MOSTNY, GRETE, Culturas Precolombinas de Chile, Editorial Universitaria, Santiago, 1960.

MUNIZAGA, CARLOS, Notas sobre la adaptación al medio ambiente físico de Chiloé. Vivienda y Vestuario. Trabajo de Antropología Social. Universidad de Chile. Santiago. Chile. 1971.

MUNIZAGA, JUAN, Reconocimiento antropológico de la Provincia de Chiloé, Departamento de Ciencias Antropológicas y Arqueológicas. U de Chile. Santiago. Chile. 1996.

URBINA, RODOLFO, Los pueblos de Chiloé, génesis de un periplo Urbano, en: revista CA, No 78 , pp. 3437, 1994.

URBINA, RODOLFO, La vida en Chiloé en los tiempos del fogón. 1900 - 1940, Valparaíso. Chile. Editorial UPLA. 2002.

VENEGAS, MELCHIOR, Cartas anuales de la provincia del Paraguay, Chile y Tucumán, Universidad Nacional de Buenos Aires, Facultad de Filosofía y Letras, Documentos para la Historia Argentina, tomos 19 y 20, Bs. Aires, 1927-1929.

VIDAL DE LA BLACHE, PAUL. Les genres de vie dans la géographie humaine. Annales de Géographie. Vol. XX. Paris. Francia. 1922. 